\title{
O Químico Francisco Mendes Cardoso Leal Júnior: Contributo para a sUa História
}

\author{
Madalena Romão Mira \\ Biblioteca da Universidade Autónoma de Lisboa \\ mmira@universidade-autonoma.pt
}

químico Francisco Mendes Cardoso Leal Júnior (1798-1867), hoje quase desconhecido, foi, provavelmente, o primeiro preparador de Química da Escola Politécnica, mas também farmacêutico, funcionário da Casa da Moeda e proprietário de um laboratório de Química aplicada às artes, entre outras actividades químicas.

INTRODUÇÃO

Ao fazer um levantamento do tecido industrial da zona da Trindade em meados do século XIX deparou-se-nos a figura de Leal Júnior, pessoa sobre a qual pouco estava escrito. A sua multiplicidade de valências despertou-nos a curiosidade de tal forma que procurámos saber o mais possível sobre ele, conscientes que a História da Ciência é feita de descobertas e invenções, de progresso, de técnicas e tecnologia mas, antes de tudo, é feita por pessoas.

Não raras vezes os protagonistas são chamados à "praça pública” do olhar investigador, ou simplesmente do curioso, sempre em vizinhança com a sua produção científica e ou intelectual. Assim, é comum dizer-se que pouco se sabe acerca de fulano, que se desconhece quase tudo acerca de beltrano ou ainda que se perdeu o rasto a sicrano porque a visão recai na obra e não na pessoa, sendo esta, frequentemente, secundarizada, logo, desvalorizada.

Francisco Mendes Cardoso Leal Júnior ocupa um lugar na Ciência em Portugal, como “... aquele que foi provavelmente o primeiro preparador de Química da Escola Politécnica” [1].

Um preparador era alguém "Destinado fundamentalmente a coadjuvar o lente, poupando-o às tarefas menores, preparatórias dos trabalhos práticos, para apoio às cadeiras, e de investigação, o preparador podia ver ainda o alcance das suas funções - e isto ditado em geral por necessidades conjunturais - oscilar do quase servente de laboratório até o quase assistente da cadeira” [2].

Porém, qual estrela com várias pontas, Leal Júnior foi um cientista cuja actividade se expandiu muito para além dos bancos da escola, pessoa considerada no meio, como o atesta o facto de ter pertencido à Comissão para a promoção da indústria portuguesa em Londres, em 1851 e ainda como fabricante dos mais variados produtos, brutos à vista do nome, mas com aplicações na arte da tinturaria, da Medicina ou no fabrico de bebidas.

Este texto visa dar a conhecer melhor um homem que, como muitos, concorreu para o progresso da Ciência, sendo a sua pegada imerecidamente pouco visível.

\section{DeDICAÇÃo À QuímICA}

Francisco Mendes Cardoso Leal Júnior nasceu na paróquia do Monte da Caparica a 6 de Maio de 1798, filho de Joaquim Pedro, proprietário, e de Maria dos Prazeres, ambos da Caparica [3].

Os pormenores da deslocação para Lisboa são-nos desconhecidos; segundo Isabel Cruz, podemos encontrá-lo “... nos livros de matrículas do Curso de Física e de Química, de Luís da Silva Mouzinho de Albuquerque (que funcionou no Laboratório de Química da Casa da Moeda entre 1823 e 1828), ano lectivo de 1824/1825 - parte de Física, já com 25 anos e identificado como Farmacêutico. Não temos qualquer informação sobre o estabelecimento em que deveria praticar, no entanto, vinte anos depois era proprietário de um Laboratório Químico sito na antiga igreja demolida do Carmo” [4].

No ano em que Portugal assiste à entrada da máquina a vapor para efeitos industriais, 1835, “... a Casa da Moeda é palco de grandes reformas e transformações, sobretudo motivadas por obras que visavam a instalação de uma máquina a vapor, para cunhar moedas, vinda de Inglaterra, facto que dá origem a grandes modificações na organização dos espaços destinados às diversas actividades, gerando descontentamentos e até a demissão de alguns dirigentes” [5].

Francisco Leal Júnior continua a trabalhar e temos notícias que a sua actividade não se desenvolve apenas em laboratório mas tem uma vertente prática; assim, o Diccionário de Medicina Popular [6] afirma que “As águas do Estoril são aconselhadas em banhos, contra as moléstias de pelle, escróphulas, rheumatismo chrónico e paralysias”, conclusão a que se chega depois da água ter sido analisada por Leal Júnior, informação essa também publicada no Bolletim das Sciências Médicas de Lisboa [7].

Por essa altura “... a atividade do Laboratório [da Casa da Moeda] acaba por se desvanecer e os instrumentos que apetrechavam o Laboratório e que serviam para as demonstrações ali realizadas acabam sendo dispersados por outras instituições de Lisboa” [8]. Sendo a criação da Escola Politécnica datada de Janeiro de 1837 estamos em crer que, 
pelo menos parte desses instrumentos e demais apetrechos, foram deslocados para lá.

As mudanças na Casa da Moeda são a imagem dos tempos conturbados que se vivem; Lisboa assiste a convulsões políticas, económicas e sociais que se sucedem. As Cortes estão convocadas com o objectivo de elaborar o texto constitucional que, em Abril de 1838, é jurado pela rainha D. Maria II.

Nesse mesmo ano reencontramos Leal Júnior, num decreto existente no Arquivo Nacional Torre do Tombo, datado de 12 de Março de 1838, que o declara Preparador do Laboratório da Casa da Moeda e Ajudante do Contador da dita casa De uns meses mais tarde, 8 de Junho de 1838, é uma Carta a identificá-lo como Preparador do Laboratório Químico e Ajudante do Ensaiador da Casa da Moeda [9]. Trabalha ainda na Rua de S. Paulo, que tinha instalações e recursos notáveis para a época [10], no início do século? Ou terá passado para a Escola Politécnica?

A resposta parece ser positiva em ambas as perguntas, (veremos que persiste a sua ligação à Casa da Moeda) e mais ainda: em 1841 temos notícia dele como $1 .{ }^{\circ}$ Operador da Sociedade Farmacêutica de Lisboa. A menção é feita em Corografia, ou Memoria economica, estadistica, e topografica do reino do Algarve [11], a propósito da análise de sal em Tavira, Alvor e Lagos. Não é de estranhar esta actividade pois, como veremos adiante, Leal Júnior, para além das funções profissionais na Casa da Moeda, era fabricante de sulfatos, na Trindade, pelo menos desde 1845.

É precisamente aí, nos terrenos das Capelas Velhas do extinto Convento do Carmo que, na qualidade de Preparador de Química da Escola Politécnica, é autorizado a fazer uso do terreno para abrir um Curso de Química aplicado às Artes. A Portaria é de 26 de Fevereiro de 1845 e menciona que foi requerida uma licença por doze anos, sendo, à data da documentação consultada por Carlos Beato, 1857, uma renovação [12], logo, nessa data, Leal Júnior ainda é Preparador de Química na Escola Politécnica.

A autorização terá sido concedida em 1845, caso contrário não se pedia a renovação e, como veremos adiante, em 1857 não só pede a dita renovação como também solicita à Câmara de Lisboa o aumento de um prédio na vizinha Rua da Trindade.

O ano de 1846 traz alegria e divertimento à sociedade lisboeta, com a inauguração do Teatro Nacional D. Maria II, em Abril, e fecha com a criação de uma instituição determinante nas dinâmicas financeiras do país: em Dezembro dá-se a fusão entre o Banco de Lisboa e a Companhia Confiança Nacional, nascendo aquele que ainda hoje emite a moeda nacional, o Banco de Portugal.

Francisco, se era adepto de teatro, terá então assistido à referida inauguração, mas não sozinho: em 2 de Março de 1846 casou, na freguesia do Sacramento em Lisboa, com Carlota Emília Cardoso [13] e, logo a 13 de Maio do mes- mo ano, é emitida em seu nome uma carta, por decreto, nomeando-o 2. ${ }^{\circ}$ Ensaiador da Casa da Moeda e Papel Selado [14].

Os Ensaiadores, como vem estipulado pelo menos desde o séc. XVII, “... devem ser oficiais da maior confiança da Casa da Moeda, de boa consciência e fama, por se fiar deles o exame da boa qualidade dos metais de que se compõe a moeda” [15].

O Ensaiador usava a copella ou copelha, um pequeno vaso onde fazia fundir o metal nas quantidades, pesos e tamanhos certos, repetindo o processo tantas vezes quantas as necessárias, até dar o trabalho como pronto; sobre as dinâmicas dos laboratórios da Casa da Moeda veja-se o trabalho de Márcia Helena Ferraz [16].

Ainda no início do século os conhecimentos de metalurgia do Intendente Geral das Minas e Metais do Reino, José Bonifácio, foram preponderantes para dirigir o Laboratório da Casa da Moeda e não terão sido alheios a todo o rol de instruções [17] que, mais tarde no Brasil, se proclamaram para as matérias dos exames dos concorrentes aos empregos científicos e artísticos da Casa da Moeda, para além dos conhecimentos químicos, complexos, tinham também de saber gramática nacional e francesa (leitura e versão); aritmética (operações gerais); cálculo de complexos; teoria e prática das regras de proporção e sua aplicação, inclusive as regras de liga; metrologia (conhecimento de todas as partes do sistema métrico). Seguem-se os conhecimentos sobre ensaios químicos, propriedade de gases e líquidos, areometria, para além de distintas reacções e balanços químicos com diferentes e inúmeros materiais.

Não há motivos para crer que as instruções em Portugal fossem muito diferentes, o que nos permite ver um Leal Júnior culto, com conhecimentos da sua área de actividade, mas não só. Desconhecem-se detalhes da sua situação financeira, que não devia ser limitada, face aos seus empreendimentos. Não encontrámos informação para a década de 40 do século XIX, mas de acordo com a Colecção oficial de legislação portuguesa, em 1863, um ensaiador auferia um vencimento anual de $250 \$ 000$ réis [18] "para além das avenças de metais para os ensaios” [19].

\section{RECONHECIMENTO}

A autoridade de Francisco Leal Júnior no mundo da Química é-lhe reconhecida quando integra a “... Comissão de Química, do Júri da Exposição da Indústria, realizada pela Sociedade Promotora da Indústria Nacional em 1849, junto com, precisamente, Júlio Máximo de Oliveira Pimentel, para além de José Lourenço da Luz e de Francisco António Pereira da Costa” [20]. As Comissões, para além das Artes Químicas, são também de Tecidos, Artes Mecânicas e Belas-Artes [21].

Não é pois de estranhar que, dois anos mais tarde, em 1851, o encontremos com funções destacadas como um dos elementos do elenco da Comissão Industrial que representou 
Portugal na Exposição Universal de Londres no mesmo ano, presidida pelo Conde de Tomar, e constituída também por Charles Bonnet, o Visconde da Carreira, o Barão da Luz, o Barão de Alcoentre, Francisco Tavares de Almeida Proença, Joaquim José da Costa Macedo, Joaquim Larcher, José Ferreira Pinto Basto e secretariada por Sebastião José Ribeiro de Sá [22].

Esta Comissão, cujo nobre objectivo era promover a indústria portuguesa na poderosa capital inglesa, foi largamente difundida, surgindo em periódicos como a Revista popular: semanario de litteratura, sciencia, e industria [23] ou, além-mar, no Diário de Pernambuco [24].

Nota-se-lhe a ausência na Exposição de Paris em 1855. Mantê-lo-ia o Curso de Química aplicado às Artes no Carmo muito ocupado?

\section{SUPOSIÇÕES}

A Câmara Municipal de Lisboa regista no seu Arquivo Histórico um pedido de Francisco Mendes Cardoso Leal para aumentar um prédio na rua da Trindade, $n^{\circ} 30$ [25], em 1857. Exactamente no mesmo ano, um seu vizinho, Bernardo Luizelo, é proprietário de uma fábrica de gesso, na mesma rua, $n^{\circ} 7$ [26] e, ainda na mesma rua, está outro ilustre, Manuel Moreira Garcia, proprietário da Fábrica de Cerveja Trindade, localizada na rua imediatamente a seguir, dita Nova da Trindade.

Porque se mencionam aqui outros moradores da mesma rua? Se atentarmos na lista de produtos com que Francisco Leal Júnior concorreu à Exposição em Londres, percebe-se que a vizinhança era, possivelmente, também clientela.

A Revista Universal Lisbonense [27] enumera a participação de Francisco como produtor, fabricante e expositor (sendo também membro da Comissão, como já vimos), tendo ganho uma medalha de prémio pela sua Essência de Alfazema [28].

Assim, enumeram-se os produtos que levou a Londres, com toda a informação disponível na citada Revista Universal Lisbonense [29]:

- 31 - Carbonato de potassa - sal de tartaro. Expositor e fabricante. Laboratório chimico, analítico e consultivo, estabelecido em Lisboa, no Carmo. Obtido pela combustão do sarro do vinho. Matéria-prima portugueza muito abundante.

- 32 - Bitartarato de potassa - Cremor de tartaro. EXpositor e fabricante. Obtido do tartaro crú, ou sarro de vinho.

- 65 - Sulphato de ferro - Caparosa verde. Expositor e productor. Extrahido de pyrites de ferro natural. Empregado nas artes de tinturaria e estamparia [30]

- 66 - Sulphato de cobre - Caparosa azul. Expositor e productor. Extrahido do acido sulphúrico sobre o cobre. Emprega-se na tinturaria.
- 67 - Sulphato de cobre ammoniacal. Expositor e productor. Empregado nos fogos artificiaes [31]

- 73 - Chromato de chumbo. Expositor e fabricante. Empregado nas pinturas a oleo.

- 74 - Iodureto de potassium . Expositor e fabricante. Empregado na medicina [32]

- 78 - Bioxido de mercurio. Expositor e fabricante. Empregado na medicina veterinária.

- 79 - Bichlorureto de mercúrio - Solimão. Expositor e fabricante. Empregado na medicina.

- 497 - Essencia de alfazema. Expositor e fabricante.

- 498 - Essencia de rosmaninho. Expositor e fabricante.

- 499 - Essencia de zimbro ou junípero. Expositor e fabricante.

- 500 - Essencia de limão. Expositor e fabricante.

- 501 - Acido cítrico. Expositor e fabricante.

- 502 - Acido tartárico. Expositor e fabricante.

- 515 - Alcool absoluto. Expositor e fabricante.

Se o vizinho Moreira Garcia vendia cerveja e limonadas ao virar da esquina no 44 da Rua Nova da Trindade, será muito arriscado colocar a hipótese de o laboratório de Leal Júnior ter servido a Moreira Garcia para apurar ou aperfeiçoar os processos de destilação? As essências de limão e o ácido cítrico terão tido o galego como cliente?

Por outro lado, Luizelo, com os seus fornos para o gesso, teria de alguma forma sido associado ao produtor de sulfatos, uma vez que ambos concorrem em produtos úteis para a agricultura?

Tendo em conta que, numa altura em que os recursos não são abundantes, e que se verifica co-existirem com muita proximidade comerciantes cujos interesses convergem, não obstante não dispormos de dados sobre estas questões, não deixamos de as colocar, perante uma certeza: a Trindade era uma zona industrializada da cidade.

Uma palavra sobre o misterioso Moreira Garcia e a proximidade de vidas destes dois homens: nascem com dois anos de diferença; este galego veio para Lisboa, provavelmente, em 1819, data não distante para Leal Júnior ter também vindo definitivamente para a capital; por outro lado, o processo do fabrico de cerveja não podia privar Garcia de conhecimentos mínimos no âmbito da química; são vizinhos uma vida inteira, ambos têm estabelecimentos comerciais quase confinantes e morrem com cinco meses de diferença, na mesma rua e ambos sem filhos. Fica por estudar a relação entre ambos que, garantidamente, existiu.

Leal Júnior é promovido a Primeiro Ensaiador da Casa da Moeda e Papel Selado a 9 de Julho de 1860 [33]. 
Isabel Cruz afiança que em 1865 o seu laboratório químico se mantem na Rua da Trindade, $\mathrm{n}^{0} 22$ e que ainda lá funciona na década de 80, mas já com Júlio Moreira Feyo e depois de ter sido expandido, entre os $n^{\circ} \mathrm{s} 18$ a 26 [34]. Porém, nem tudo era Laboratório: Francisco vivia no $n^{\circ} 20$, como veremos adiante.

Os prestigiados periódicos científicos da época também o nomeiam: precisamente em 1865 a Gazeta Médica de Lisboa identifica-o como tendo feito a análise da água do Hospício de Santo António do Estoril [35]. Infelizmente não dá informação sobre se o fez na qualidade de funcionário da Sociedade Farmacêutica, como sabemos que era em 1841, ou se seria no âmbito da sua empresa.

\section{ApONTAMENTO FINAL}

Às dez horas da manhã da quinta-feira 28 de Novembro de 1867 morre Francisco Mendes Cardoso Leal Júnior [36].

Faleceu na sua residência na casa $\mathrm{n}^{\circ} 20$ na Rua da Trindade. O registo de óbito identifica-o como Chimico, natural da Caparica, com 70 anos que, sabemos pelo registo de nascimento, eram ainda 69. Mais informa o mesmo registo que fez testamento e não deixou filhos. Foi enterrado no jazigo n ${ }^{\circ} 609$ do cemitério dos Prazeres.

Com uma vida dedicada à Química, passou pela Escola Politécnica, pela Sociedade Farmacêutica e pela Casa da Moeda; como funcionário destas instituições desenvolveu trabalho prático como analista e, em simultâneo, como comerciante e como educador.

O seu Curso de Química, por ser aplicado às Artes, indica-nos uma pessoa que não se reduzia à ciência "pura e dura”, o que, aliado aos conhecimentos necessários para ser Ensaiador, nos levam a delinear um homem com múltiplos interesses, aptidões e talentos.

\section{REFERÊNCIAS E NOTAS}

[1] I. Cruz, Preparadores de química da Escola Politécnica (1837 - 1856). Disponível em http://triplov.com/isabel_ cruz/prepara_dores/preparador.html (acedido a 12 de Março de 2014)

[2] Idem

[3] Arquivo Distrital de Setúbal, "Livro de Registo de Baptismos. Paróquia do Monte de Caparica (1798/1804)”, sem $\mathrm{n}^{\circ}$, p. 33v e 34. Foram seus padrinhos Francisco Mendes Cardoso, morador em Areeiro, e Leocádia Margarida dos Santos, moradora na freguesia da Sé em Lisboa.

[4] I. Cruz, op. cit

[5] “O Laboratório Químico da Casa da Moeda no séc. XIX”, Matriz: Boletim Interno da INCM. Lisboa: INCM. (Out. 2012), p. 11. Disponível em https://www.incm.pt/portal/arquivo/matriz/201210.pdf (acedido a 12 de Março de 2014)

[6] L.N. Chernoviz, "Diccionário de Medicina Popular e das Sciências acessórias para o uso das famílias contendo a descripção Causas, symptomas e tratamento das moléstias;
As receitas para cada moléstia; As plantas medicinaes e as alimentícias; As águas mineraes do Brasil, de Portugal e de outros paizes; E muitos conhecimentos úteis”, $5^{\text {a }}$ ed, Pariz, em casa do autor Rua Raynouard, 24: 1878, p. 76

[7] Bolletim das Sciências Médicas de Lisboa, Tomo II (1835) 217

[8] “O Laboratório Químico da Casa da Moeda no séc. XIX”, Matriz: Boletim Interno da INCM. Lisboa: INCM. (Out. 2012), p. 11. Disponível em https://www.incm.pt/portal/arquivo/matriz/201210.pdf (acedido a 12 de Março de 2014)

[9] Arquivo Nacional Torre do Tombo - Francisco Mendes Cardoso Leal Júnior. Decreto. Preparador do Laboratório da Casa da Moeda e Ajudante do Contador da dita casa. Registo Geral de Mercês, D. Maria II, liv.7, fl.235v-236, 12 de Março de 1838.

Arquivo Nacional Torre do Tombo - Francisco Mendes Cardoso Leal Júnior. Carta. Preparador do Laboratório Químico e Ajudante do Ensaiador da Casa da Moeda. Registo Geral de Mercês, D. Maria II, liv.7, fl.241-241v, 6 de Junho de 1838

[10] "O Laboratório Químico da Casa da Moeda no séc. XIX”, Matriz: Boletim Interno da INCM. Lisboa: INCM. (Out. 2012), p. 11. Disponível em https://www.incm.pt/portal/ arquivo/matriz/201210.pdf, p. 9. (acedido a 12 de Março de 2014)

[11] J.B.S. Lopes, Corografia, ou Memoria economica, estadistica, e topografica do reino do Algarve. Faro: Algarve em Foco Editora (1841) 131. O autor é sócio da Academia das Ciências

[12] C.A.S. Beato, “Os liceus e as ciências (1836-1860): um estudo sobre o processo de criação das disciplinas de ciências físicas e naturais nos liceus portugueses”, Tese de Doutoramento em Educação, Área de especialização - História da Educação, Instituto de Educação da Universidade de Lisboa, 2011. A páginas 192, nota 5, o autor menciona um Processo para a renovação de uma licença de estabelecimento de um laboratório químico e a cota do ANTT MR, M 3578. Disponível em http://repositorio.ul.pt/bitstream/10451/5486/1/ ulsd062095_td_Carlos_Beato.pdf (acedido a 12 de Março de 2014)

[13] Filha de António Cardoso Pereira de Senna Correa e de Maria da Anunciação Cardoso, natural e moradora na freguesia de Santa Catarina, em Lisboa. Foram testemunhas Joaquim Plácido de Macedo, morador na Rua da Quintinha, n 29, freguesia das Mercês, e António Cardoso Pereira de Senna Correa, morador na Calçada do Combro, freguesia de Santa Catarina, o sogro. Arquivo Nacional Torre do Tombo - Registo de Casamentos. Paróquia de Sacramento (1845-1859), sem $n^{\circ}$, p. 8

[14] Arquivo Nacional Torre do Tombo - Francisco Mendes Cardoso Leal Júnior. Carta. 2. ${ }^{\circ}$ Ensaiador da Casa da Moeda e Papel Selado, por decreto. Registo Geral de Mercês, D. Maria II, liv.27, fl.225v, 13 de Maio de 1846

[15] J.R. Valle, "Classificação geral da legislação portugueza: desde a publicação do Código Philipino até à Data”, Typ. da Sociedade Propagadora dos Conhecimentos Úteis, Lisboa (1841) 349

[16] M.H.M. Ferraz, O Laboratório Químico da Casa da Moeda de Lisboa no Século XIX: Espaço Físico e Instrumentos, in 
Colóquio Internacional "La Mémoire de la Science. Archives et collections, sources de l'histoire des sciences et des techniques”, Cité des Sciences et de l'Industrie, Muséum National d'Histoire Naturelle, Institut de France, Paris, 27-29 de Junho de 2000

[17] Coleção das Decisões do Governo do Império do Brazil em 1860, Typografia Nacional, Rio de Janeiro (1861) tomo XXIII, p. 471 e segs

[18] Um delegado da polícia aufere $700 \$ 000$ réis anuais e um escrivão nas comarcas de Lisboa e Porto, 200\$000 réis; para mais comparações ver J.M.J.C. Leite e Vasconcellos, “Colecção oficial de legislação portuguesa”, Imprensa Nacional, Lisboa (1864), 308 e 324

[19] Idem, p. 400.

[20] I. Cruz, op. cit.

[21] J.S. Ribeiro, "História dos Estabelecimentos scientificos, literários e artísticos de Portugal, nos sucessivos reinados da monarchia”, Typografia da Academia Real das Sciencias, Lisboa (1879) tomo VIII, 396. Menção a Leal Júnior p. 398

[22] V.M.V.S. Leitão, “Assentar a primeira pedra: As primeiras Comissões Geológicas portuguesas (1848-1868)”, Dissertação apresentada para obtenção do Grau de Doutor em História e Filosofia das Ciências, especialidade de Epistemologia das Ciências, pela Universidade Nova de Lisboa, Faculdade de Ciências e Tecnologia, 2004, 58. Disponível em http://run.unl.pt/bitstream/10362/1118/1/leitao_2004. pdf (acedido a 12 de Março de 2014)

[23] Revista popular: semanario de litteratura, sciencia, e industria, Ano XXVII, Vol. 4, (1851) 17

[24] Diário de Pernambuco, Ano XXVII, nº 32, p. 1. Disponível em http://ufdc.ufl.edu/AA00011611/06317/1j (acedido a 12 de Março de 2014)

[25] Câmara Municipal de Lisboa - Prospecto do prédio que Francisco Mendes Cardoso Leal pretende acrescentar na rua da Trindade, $n^{\circ}$ 30. Arquivo Histórico, Ref. PT/ AMLSB/CMLSB/ADMG-E/23

[26] O Almanak Popular já o identifica nesta actividade e localização em 1849. Almanak Popular para o Anno de 1849. Lisboa: Imprensa Nacional, 1848, p. 117

[27] Revista Universal Lisbonense: jornal dos interesses physicos, moraes e litterarios por uma sociedade estudiosa, Imprensa Nacional, Lisboa (1852), vol. 11, pp. 39, 63, 124, 125, 280

[28] Idem, p. 135

[29] Todos mencionam o seu nome e a informação "Fábrica, vide $n^{\circ} 31$ ”, dados que se não incluíram por serem repetitivos.

[30] É usado como corante.

[31] Dá cor ao fogo-de-artifício.

[32] Usado também na fotografia. Na medicina utiliza-se como protector em tratamentos radiológicos.

[33] Arquivo Nacional Torre do Tombo - Francisco Mendes Cardoso Leal Júnior. Apostila. Primeiro Ensaiador da Casa da Moeda e Papel Selado. Registo Geral de Mercês, D. Pedro V, liv.18, fl.41v, 9 de Julho de 1860.

[34] I. Cruz, op. cit

[35] Gazeta Médica de Lisboa, Imprensa Nacional, Lisboa (1865) 231

[36] Arquivo Nacional Torre do Tombo -Registo de Óbitos. Paróquia de Sacramento (1856/1870). Nº3, p. 194v

\section{Actualidades Científicas}

\section{GenOtoXicidade de nanOPARTíCULAS DE $\mathrm{TIO}_{2}$}

O dióxido de titânio $\left(\mathrm{TiO}_{2}\right)$ é considerado um semicondutor quase ideal para fotocatálise devido à sua elevada estabilidade, baixo custo e também porque é seguro tanto para os seres humanos como para o meio ambiente.

As nanopartículas de $\mathrm{TiO}_{2}$ são utilizadas em muitos produtos, tais como cosméticos, incluindo protectores solares, pastas dentífricas, produtos farmacêuticos e como aditivos em alimentos. Também têm aplicações nos campos da electrónica, óptica, genómica, proteómica, e da química bioanalítica, nomeadamente em biossensores, devido à sua elevada área superficial, reactividade química acrescida e mais fácil entrada nas células. As nanopartículas de $\mathrm{TiO}_{2}$ podem entrar nos aquíferos também a partir de restos de plástico, vidro ou detritos metálicos com revestimento destas nanopartículas. Os efluentes das estações de tratamento de águas residuais são os principais responsáveis pela contaminação das águas dos rios pelas nanopartículas de $\mathrm{TiO}_{2}$.

Pakrashi et. al (2014) usaram extremidades da raiz de Allium cepa (cebola vermelha) que foram tratadas com dispersões de nanopartículas de $\mathrm{TiO}_{2}$ em quatro concentrações diferentes (12,5; 25; 50; $\left.100 \mu \mathrm{g} / \mathrm{mL}\right)$. Através de técnicas de microscopia óptica, de fluorescência e confocal a laser, detectaram aberrações cromossómicas nas raízes da cebola vermelha. A bio-absorção de $\mathrm{TiO}_{2}$ na forma de nanopartículas causou, provavelmente, a produção de espécies reactivas de oxigénio que por sua vez originaram as aberrações cromossómicas e os danos no ADN observados. Os autores concluíram que a exposição a nanopartículas de $\mathrm{TiO}_{2}$ é capaz de induzir genotoxicidade em plantas em concentrações muito baixas $(12,5 \mu \mathrm{g} / \mathrm{mL})$ devido à internalização das partículas e ao stress oxidativo daí resultante.

(adaptado de S. Pakrashi, N. Jain, S. Dalai, J. Jayakumar, P.T. Chandrasekaran, A.M. Raichur, N. Chandrasekaran, A. Mukherjee, PLOS ONE 9 (2014) e87789)

António Mendonça (mendonca@ubi.pt) 


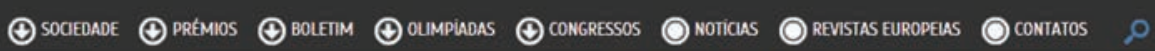

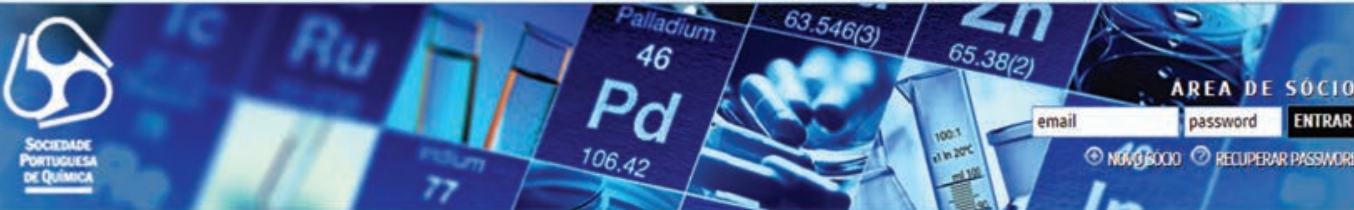

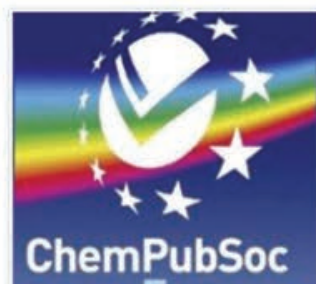

OEMPUESOCBUAOFENENSETIRS

Greetings and salutations, this newsletter is produced for our global for the member Chemical Societies that make up ChemPubSoc Europe

\section{chemRus 2014}

VENCHDROEMFU: 2014

Em 2014 howve um aumento significativo de participaçóes, um total de 20 escolas com 27 videos.

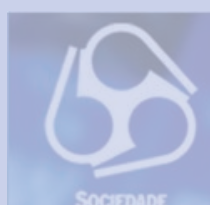

\section{Visite o site da SPQ}

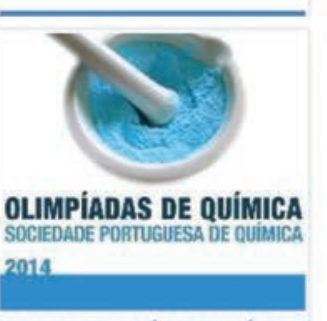

VENCHOFES OUMPINDAS DE QUIMCA: $20 \mathrm{M}$

As Finais Nacionais realizaram-se Sábado, dia 3 de Maio. A Final das Oumpiadas de Quimica Junior

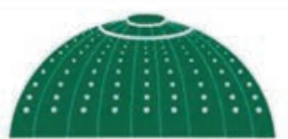 \\ XXENCONTRO LUSO-GALEGO DE QUÍMICA}

YXENCONIROUUSO-GAEGO DEQUIMCA

Passados 30 anos sobre o nascimento desta ideia estamos a celebrar a realizaçă do XX Encontro Luso. Gartual de 26 a 28 de novembro de

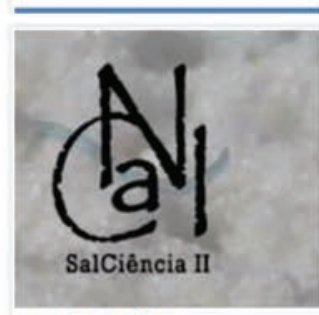

PROEECTOSALOÂVAL

Inspirado num composto quimico tão comum como o sal - cloreto de sódio - wilgarmente conhecido como sol de

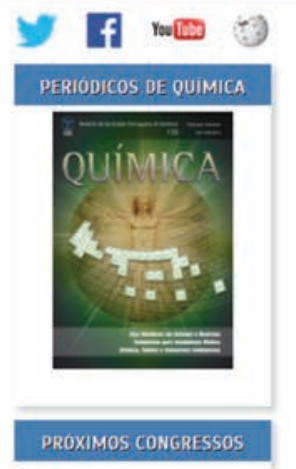

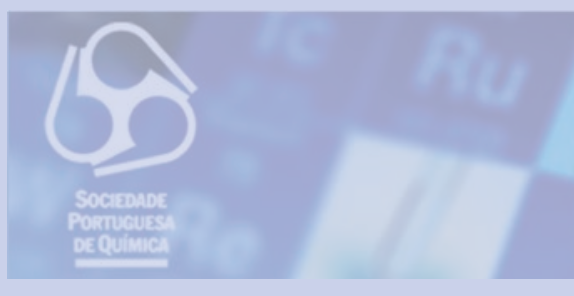

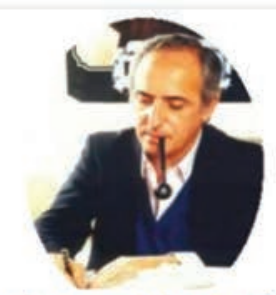

Prémo Aurerto POM

ACAPLOSC ROMWVO

Professor Catedrático e Coordenador do Grupo de Química Organometálica do Instituto de Tecnologia Química e Biológica da Universidade Nova de Lisbos.

\section{www.spq.pt}

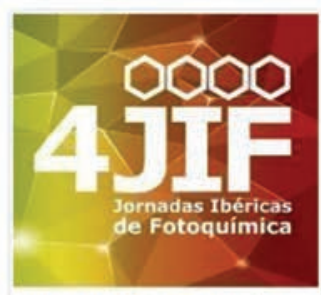

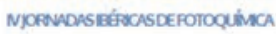

Organizadas pelo IST, pela SPQ e usboa, de 29 de Junho a 2 de futho de 2014

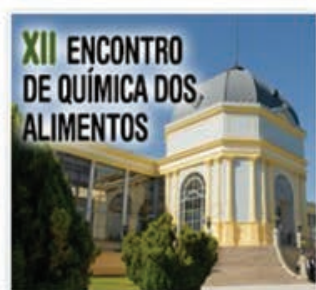

Xa BNCONIRO DE QUimCA DOS

Organizado pela Divisão e Química dos Alimentos da SPQ e a realizar no Instituto Superior de Agronomia, de 10 a 12 de Setembro de 2014

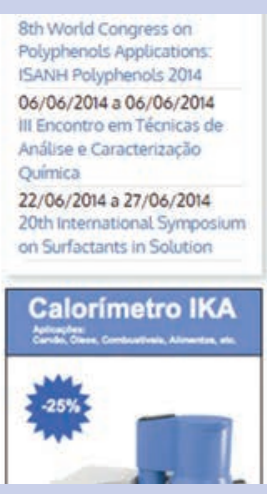

2019 